Document downloaded from:

http://hdl.handle.net/10251/60827

This paper must be cited as:

Wegrzyn, M.; Juan Nadal, S.; Benedito, A.; Giménez Torres, E. (2013). The influence of injection molding parameters on electrical properties of PC/ABS-MWCNT nanocomposites. Journal of Applied Polymer Science. 130(3):2152-2158. doi:10.1002/app.39412.

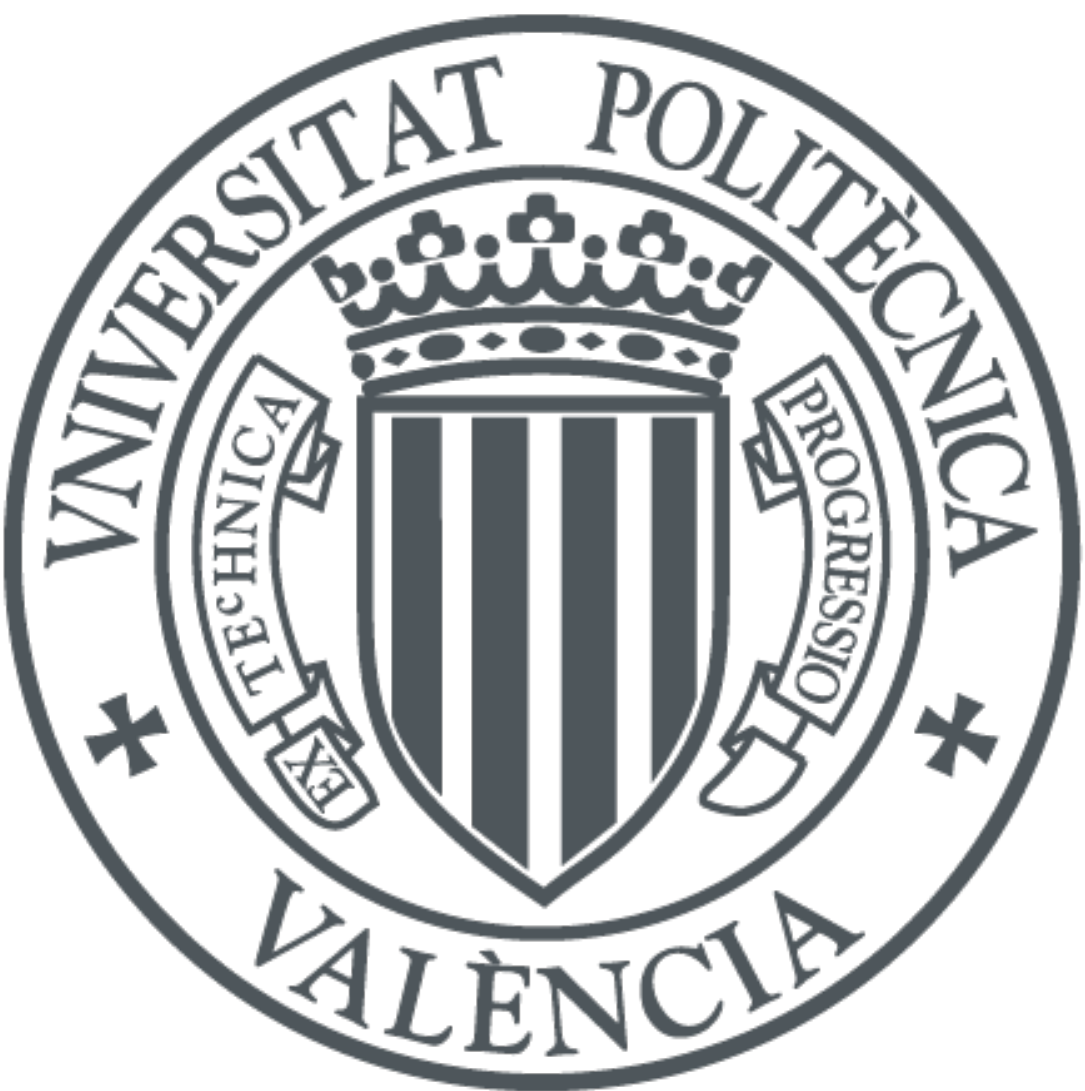

The final publication is available at

http://dx.doi.org/10.1002/app.39412

Copyright Wiley

Additional Information 


\section{The influence of injection molding parameters on electrical} properties of PC/ABS-MWCNT nanocomposites

\begin{tabular}{|r|l|}
\hline Journal: & Journal of Applied Polymer Science \\
\hline Manuscript ID: & APP-2013-01-0132.R1 \\
\hline Wiley - Manuscript type: & Research Article \\
\hline Keywords: & blends, thermoplastics, nanotubes, graphene and fullerenes, microscopy \\
\hline \multicolumn{2}{|c}{}
\end{tabular}

\section{SCHOLARONE $^{\text {M }}$ \\ Manuscripts}

John Wiley \& Sons, Inc. 
The influence of injection molding parameters on electrical properties of PC/ABSMWCNT nanocomposites.

\author{
Marcin Wegrzyn ${ }^{\dagger}$, Sara Juan $^{\dagger}$, Adolfo Benedito $^{\dagger}$, Enrique Giménez $^{\ddagger}$ \\ ${ }^{\dagger}$ Instituto Tecnológico del Plástico (AIMPLAS), Calle Gustave Eiffel 4, 46980 Paterna (SPAIN) \\ ${ }^{\ddagger}$ Instituto de Tecnología de Materiales. Universidad Politécnica de Valencia, 46022 Valencia (SPAIN) \\ Correspondence to: Marcin Wegrzyn (E-mail: marcin@aimplas.es)
}

\title{
ABSTRACT
}

The influence of injection molding parameters on electrical properties and morphology of PC/ABSMWCNT nanocomposites is presented in this work. Investigation is based on the masterbatch of 5.0 wt. \% carbon nanotubes obtained by melt-mixing. Further processing includes dilution of this nanocomposite to desired concentrations on twin-screw extruder and injection molding or direct dilution of masterbatch in injection molding. Additionally, reprocessing of materials formed by compression and injection molding is presented along with the change in electrical conductivity. Morphology differs strongly between the two processing paths showing change in agglomeration behavior between nanotubes concentrations. Electrical properties show dependence on injection velocity and melt temperature in both applied processing paths. Moreover, electrical conductivity recovery is proved after injection and compression molding.

KEYWORDS Thermoplastics, Blends, Carbon Nanotubes, Injection Molding, Microscopy

\section{INTRODUCTION}

Multi-walled carbon nanotubes (MWCNT) with a unique structure and properties became an important group among the carbon-based nanostructured additives of commercial plastics. MWCNT in nanocomposites can boost electrical and thermal conductivity ${ }^{1-3}$ by orders of magnitude over the 
performance achievable with traditional carbon fillers in similar weight percentages ${ }^{4}$. Nanocomposites reach volume resistivity on the level of $10^{2} \Omega \mathrm{cm}^{-1}$, which is the improvement of over ten orders of magnitude comparing to the matrix values ${ }^{5}$. The values reported for mechanical properties ${ }^{6}$ and electrical depend on the quality of filler dispersion and agglomerates distribution ${ }^{1,7}$.

Injection molding, one of the common methods in plastic processing, has been reported to give less homogeneous dispersion of the carbon nanotubes (CNT) and greater dependence of the final material on processing parameters than compounding ${ }^{8-10}$. The difference of nanofiller concentration in several areas of the injected sample as a consequence of the shear-induced flow is a drawback in this technology. Studies carried out on injected samples of polycarbonate (PC) by Park et al. show the differences in nanofiller concentration between different parts of the specimen ${ }^{11}$. Though injection molding is a complex process controlled with many parameters, usually melt temperature $\mathrm{e}^{12}$ and injection speed ${ }^{8}$ are the key ones for electrical conductivity tuning. Chandra et al. reported varying electrical resistivity across the length and the width of injected PC specimen independently of process parameters ${ }^{13}$. Electrical conductivity was higher in regions farthest from injection gate and in the central part. This was explained by the shear gradient influencing carbon nanotubes entanglement. The crystallization behavior of the matrix is influenced by CNT presence in polypropylene ${ }^{14}$. In this regards, the influence of carbon nanotubes on morphology and properties of PC nanocomposites processed by injection molding have been studied by Villmow et al. ${ }^{8}$. Significant electrical conductivity improvement with the change of processing parameters has been reported for nanocomposites with 2 wt. \% and 5 wt. \% of CNT. Moreover, orientation of nanotubes in skin layer was found in samples processed with high injection speeds and reduced temperature, while the opposite sequence of parameters gave no alignment. Holding pressure and mold temperature seems to have little influence on the final properties while melt temperature is an important factor. Carbon nanotubes orientation in the final nanocomposite and agglomeration effect appearing during injection molding has been investigated with 
rheology tests showing the indication of nanofiller alignment sensitivity to the high shear conditions ${ }^{9}$. Viscoelastic properties of matrix in presence of nanofiller network is strongly related to CNT reagglomeration process. Further process modifications reported by Li et al. showed the polypropyleneMWCNT reinforced with polycarbonate micro-fibrils and the relation between dynamic sample production $^{15}$. Shear controlled orientation injection molding has been compared with the conventional process. The dynamic samples show clear improvement over the conventional ones, indicating also carbon nanotubes located in the micro-fibrils and aligned along their long axes.

In this work we study the influence of injection molding parameters on selected properties of PC/ABSMWCNT nanocomposites. Morphology determined by SEM, OM and supported by particle distribution shows relation with processing parameters. Electrical conductivity and Dynamic Mechanical properties are investigated with the respect to injection speed and melt temperature. Moreover, we prove conductivity recovery in samples reprocessed after injection molding.

\section{EXPERIMENTAL}

PC/ABS used in this work was Bayblend ${ }^{\circledR}$ T85 supplied by Bayer MaterialScience with 85 wt. \% of polycarbonate, MVR of $12 \mathrm{~cm}^{3} / 10 \mathrm{~min}$ and Vicat softening temperature of $129 \varrho^{\circ} \mathrm{C}$ (data provided by supplier). Multi-walled carbon nanotubes (MWCNT) NC7000 (produced with CCVD method) with 90\% purity were supplied by Nanocyl. Average diameter was $9.5 \mathrm{~nm}$ and average length $1.5 \mu \mathrm{m}$ (data provided by supplier).

Nanocomposites were produced with a throughput of $1 \mathrm{~kg} \mathrm{~h}^{-1}$ on the twin-screw co-rotating laboratory extruder Prism Eurolab 16 (Thermo Fisher Scientific) with barrel diameter 16mm and length-to-diameter ratio (L/D) 25. Screw profile was designed using Ludovic software (Sciences Computers Consultants). Screw speed was set to $400 \mathrm{rpm}$ while barrel temperature was $260^{\circ} \mathrm{C}$. Carbon nanotubes were added to 
the extruder with a pneumatic feeder (Brabender Technologies) together with PC/ABS pellets through the principal hopper producing masterbatch of $5.0 \mathrm{wt}$. \% MWCNT. Nanocomposites were subsequently formed by dilution of this masterbatch to the concentrations between $0.5 \mathrm{wt}$. \% and $3.0 \mathrm{wt} . \%$. PC/ABS pellets and masterbatch pellets were dried in vacuum at $120^{\circ} \mathrm{C}$ for $4 \mathrm{~h}$ before each processing stage.

Injection molding was carried out on BOY $12 \mathrm{~A}$ instrument with constant mold temperature of 70 ㅇ.

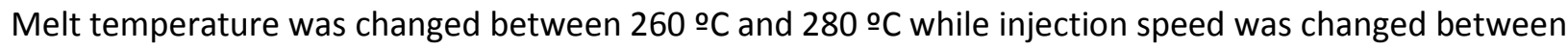
$5 \mathrm{mms}^{-1}$ and $150 \mathrm{mms}^{-1}$. The dog-bone shape specimens with the total length of $110 \mathrm{~mm}$, gauge length of $35 \mathrm{~mm}$ and thickness of $4 \mathrm{~mm}$ were used for tensile tests while the rectangular specimens, $2 \mathrm{~mm}$ thick, $10 \mathrm{~mm}$ wide and $60 \mathrm{~mm}$ long were used for thermo-mechanical tests, and electrical conductivity measurements. The specimens are prepared following slightly modified standards ISO 127 (for rectangular specimens) and ISO 527-3 (for dog-bone specimens). In order to compare results, nanocomposites samples were also prepared by compression molding at $260 \stackrel{\circ}{ } \mathrm{C}$ using Collin hydraulic press.

Morphology of nanocomposites was studied by optical microscopy (OM) on Leica DMRX microscope and by scanning electron microscopy (SEM) on JEOL 7001F scanning electron microscope. SEM samples were platinum-coated using a sputtering device (Baltec SCMCS010). Particle size calculation was carried out on Leica Materials Workstation software. Agglomeration density has been evaluated as a ratio of agglomerated area and the total investigated area of the sample.

Thermo-gravimetric analyses (TGA) were done on TA Instruments TGA Q5000. Samples were heated from $50{ }^{\circ} \mathrm{C}$ to $600{ }^{\circ} \mathrm{C}$ at a heating rate of $20^{\circ} \mathrm{C} \mathrm{min}^{-1}$ under nitrogen atmosphere and on air from $600{ }^{\circ} \mathrm{C}$ to $900^{\circ} \mathrm{C}$. 
Dynamic mechanical analysis (DMA) of the PC/ABS-MWCNT nanocomposites was done on TA Instruments DMA-2980 with dual cantilever clamp at a vibration frequency $1 \mathrm{~Hz}$, between $35^{\circ} \mathrm{C}$ and $200^{\circ} \mathrm{C}$ at scan rate $3^{\circ} \mathrm{Cmin}^{-1}$.

The electrical resistivity of the nanocomposites was measured by two- and four-point contact configuration (ISO 3915) using Keithley 2000 Multimeter source/meter. Silver electrodes were painted on the samples in order to improve contact between the sample and measuring electrodes.

\section{RESULTS AND DISCUSSION}

\section{Morphology}

SEM micrograph of PC/ABS-MWCNT nanocomposite with 5.0 wt \% of filler is shown in Figure 1. Carbon nanotubes are located mainly in polycarbonate component of the blend, distinguishable on micrographs as a smooth surface. That situation was not changed after the dilution of masterbatch presented in Figure 1 into the nanocomposites with lower filler concentrations. Additional shear in the second processing step did not improve nanofiller concentration difference between the components.

The dispersion of multi-walled carbon nanotubes and the distribution of agglomerates after the masterbatch dilution on twin-screw extruder were observed on light-transmission microscope (OM). The images of selected nanocomposites with various MWCNT contents are shown in Figure 2. Dissimilarities in the size and number of agglomerates appear between $1.0 \mathrm{wt} . \%$ and $3.0 \mathrm{wt}$. \% nanocomposites. In the sample with higher nanofiller load (Figure $2 \mathrm{~b}$ ) agglomerates are present in greater number and greater range of sizes, while in the other sample agglomerates size distribution is more homogeneous (Figure 2a). These observations are confirmed by particle distribution verification done on nanocomposites with 0.5, 1.0 and 3.0 wt. \% of MWCNT (Figure 3). Materials show content-dependent size distribution for agglomerates below $15 \mu \mathrm{m}$ with all reported nanocomposites resulting with majority of agglomerates 
located in this range. Nanofiller content 3.0 wt. \% results with greatest number of little particles, while the other materials show similar trend. Populations of detected agglomerates falling into category below $15 \mu \mathrm{m}$ are $69 \%, 61 \%$ and $75 \%$ for $0.5,1.0$ and $3.0 \mathrm{wt}$. \%, respectively (not shown here). This informs about the relative similarity between the two former nanocomposites, showing variations only for particles near the detection range. Agglomerates of size above $20 \mu \mathrm{m}$ are present for all investigated materials, though $3.0 \mathrm{wt}$ \% MWCNT gives double the number observed for $0.5 \mathrm{wt}$. \% and $1.0 \mathrm{wt}$. \%. Further particle distribution tests carried out on nanocomposites of MWCNT load between 0.5 wt. \%, 1.0 wt. \% and 3.0 wt. \% are reported in Table 1. Average particle area decreases with the increase of carbon nanotubes content. This effect is related to increased viscosity of material with higher nanofiller concentrations, providing better conditions for agglomerates breaking. Particles length show opposite trend meaning that the agglomerates have less regular shape at higher MWCNT loads. According to these results, agglomeration behavior changes with the increase of nanofiller content, moving towards the increase of agglomerates number with their size reduction.

Injection molding has been carried out with two main paths differing material type. Nanocomposites obtained by dilution of $5.0 \mathrm{wt}$. \% masterbatch in extruder were injected and compared with the direct dilution of the same masterbatch directly in injection molding. Further changes include modifications of nanofiller content and processing parameters like injection velocity and melt temperature. Morphology of specimen cross-sections after the injection molding is pictured in Figure 4. Central part of the bar (marked with the arrows) in all images is rich in nanofiller, which is explained with the skin-effect. This phenomenon is based on different behavior of nanocomposite in the core region and in the outer layer of injected part. This is coming from uneven temperature distribution inside the mold. Method based on masterbatch diluted in injection molding machine, providing one processing step less than the previous method, gives much worse morphology for both presented injection speeds. The number and size of agglomerates, as well as the layered structure are not much different between the injection velocity 50 
$\mathrm{mms}^{-1}$ (Figure 4a,c) and $100 \mathrm{mms}^{-1}$ (Figure 4b,d). For the common injection molding of pre-prepared nanocomposite the morphology is significantly better, showing more evenly distributed agglomerates in the outer region of the cross-section (Figure 4d). Moreover, appearance of layered structure with phases rich in MWCNT does not exist in this method.

Studies on distribution and content of MWCNT respecting the injection gate were carried out by thermo-gravimetric analysis (TGA) on nanocomposites. The results representative for applied experiment are explained on masterbatch sample ( $5.0 \mathrm{wt}$. \% of MWCNT) processed at $260 \stackrel{\circ}{\circ}$ with injection speed $50 \mathrm{~mm} \mathrm{~s}^{-1}$ (Figure 5). Rectangular specimen was cut into pieces and analyzed respecting the distance from gate, marked by arrow. The distribution of carbon nanotubes in the sample is not homogeneous with higher concentration on the side opposite to the injection gate. Constantly growing MWCNT load with increasing the distance from the injection gate can be explained by various flow abilities of carbon nanotubes and melted polymer. Moreover, the difference in MWCNT content in the first part of the sample is related to the disturbances of flow caused by injection gate disturbing flow.

\section{Electrical properties}

Figure 6 shows the two ways of electrical properties determination method applied in this study.

Electrodes $A$ represent sense points and electrodes $B$ represent input points used to determine volumetric electrical conductivity (four-point measurement). Two-point surface electrical conductivity measurement was performed only with electrodes $A$. Volumetric electrical conductivities of processed in comparable conditions PC/ABS-MWCNT and PC-MWCNT (reported $\mathrm{in}^{16}$ ) is significantly different (Figure 7). Masterbatch dilution is commonly applied method for production of CNT-based nanocomposites as electrical conductivity in double-processed materials reaches higher values. This is because of re-agglomeration in second step (primary- and secondary agglomeration theory) ${ }^{14}$. Double 
electrical percolation threshold was observed for the nanocomposite based on blend. First percolation appears below 0.5 wt. \% which is lower than for the PC-MWCNT nanocomposite (Figure 7). Conductivity of PC/ABS-MWCNT materials after the first percolation is higher than the related one in PC-MWCNT. Second percolation occurs between $2.5 \mathrm{wt}$. \% and $3.0 \mathrm{wt}$. \% resulting with the electrical conductivity of $0.6 \mathrm{Scm}^{-1}$.

Figure 8 illustrates electrical conductivity dependence on injection velocity for PC/ABS-MWCNT nanocomposites processed at $280 \stackrel{\circ}{ } \mathrm{C}$. The conductivity increases with nanofiller content. Electrical conductivity remains within one order of magnitude between the extreme values of each material (e.g.

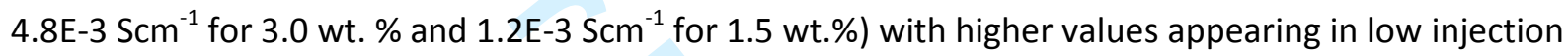
velocities. This can be explained by the theory of carbon nanotubes location in the core of specimen ${ }^{5}$ which is confirmed by Figure 4 and based on the direct influence of shear gradient for various injection velocities. Figure 9 shows the relation between surface and volumetric conductivity of samples obtained with direct masterbatch dilution in injection molding machine. Electrical conductivities are similar in low injection velocity, which proves similar morphologies in sample skin and core. From $60 \mathrm{mms}^{-1}$ onwards both conductivities are constant reaching $0.1 \mathrm{Scm}^{-1}$ and $1.1 \mathrm{Scm}^{-1}$ for surface and volumetric conductivity, respectively. The core of the specimen is MWCNT-rich in higher injection velocities and the nanofiller is oriented in the direction of the flow. This causes the increase of volume electrical conductivity giving also more differences between volume and surface conductivities. However, this phenomenon seems to have no strong relation to agglomeration. In higher injection velocities the surface conductivity is measured in low MWCNT concentration skin region, so lower values are observed. The sensitivity of the surface conductivity to the skin layer at low injection velocity was already presented by Villmow et $a l^{8}{ }^{8}$ Figure 10 shows analogous studies of both electrical conductivities dependence on melt temperature during processing. Volumetric and surface conductivity show the

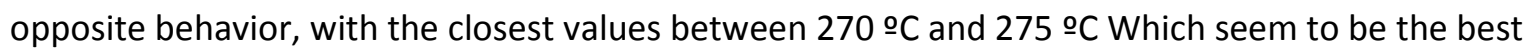


temperature to obtain homogeneous samples. However, the differences are significantly lower than the in the previous study, indicating higher influence on injection velocity on electrical conductivity.

\section{Electrical properties recovery}

Additionally, electrical conductivity recovery was investigated after various material processing routes. The experiment reported in Table 2 consists of three groups of PC/ABS-MWCNT nanocomposites. Materials were principally processed by injection molding and compression molding. This was followed by grinding the specimens and compression molding such obtained materials. Raw material for the first processing step (first compression or injection molding) was produced with masterbatch dilution in extruder (samples MB from Table 2) or in injection molding machine (samples DD). Significant differences between electrical conductivity of two different processing paths of one material are showed in Table 2. Compression molded nanocomposite with 3.0 wt. \% MWCNT shows electrical conductivity over two orders of magnitude higher than the same nanocomposites after injection molding. Nanocomposite diluted in injection molding shows lower electrical conductivities than the previous method for both velocities.

Grinding the samples after the first processing and the following compression molding of that material showed expected results of leveled electrical conductivities in the final specimens. Both, masterbatch dilution in extrusion and in injection molding, showed significant differences of conductivity between the first and the second processing. An increase of two orders of magnitude for previously injected samples was observed. Moreover, after re-compression, electrical conductivity becomes constant between both processing velocities and both methods. The final values are similar within one nanofiller concentration, which can be explained by the relaxation of carbon nanotube network. These results show that non-homogeneously distributed nanofiller leaves the possibility of electrical conductivity 
recovery after the formation of the final part. Similar effects are reported in the literature for the increase of electrical conductivity of nanocomposite melt ${ }^{1}$ or the change of electrical properties after the specimen annealing ${ }^{17}$. In both examples the changes are related to the viscoelastic relaxation of the polymer matrix allowing the reorientation of loosely-packed agglomerates and not entangled carbon nanotubes. This explanation applies also to the presented observations.

\section{CONCLUSIONS}

PC/ABS-MWCNT nanocomposites prepared by melt mixing on co-rotating twin-screw extruder and further injection molded show clear dependence on melt temperature, injection velocity and processing method. Electrical conductivity and morphology of the final material change with high- or low shear applied during processing. Basing on electrical conductivity results, the specimens show highest homogeneity at rather low shear rate, implemented by low injection velocities and moderate melt temperatures. The highest volume electrical conductivity appears also at low shear. This effect is related to the orientation of carbon nanotubes in MWCNT-rich specimen core and the existence of skin region. Moreover, strong nanofiller agglomeration is present in the final material due to the insufficient energy applied by the screw in injection molding machine. Carbon nanotube network re-creation and the recovery of electrical conductivity in re-processed PC/ABS-MWCNT nanocomposites subjected previously to various processing paths is observed. This behavior opens the possibility of MWCNT-filled nanocomposites recycling. However, this field still needs to be researched. Future research in injection molded PC/ABS-MWCNT nanocomposites should be followed by the spectroscopic study of nanofiller behavior in various regions of the specimen.

\section{ACKNOWLEDGEMENTS}


This work is funded by the European Community's Seventh Framework Program (FP7-PEOPLE-ITN-2008) within the CONTACT project Marie Curie Fellowship under grant number 238363. The authors would like to thank to Javier Gomez (SCIC, University Jaume I of Castellón) for support with electron microscopy measurements.

\section{REFERENCES AND NOTES}

1. Alig, I.; Lellinger, D.; Engel, E.; Skipa, T.; Pötschke, P.; Polymer 2008, 49, 1902-1909.

2. Pötschke, P.; Dudkin, S. M.; Alig, I.; Polymer 2003, 44, 5023-5030.

3. Duong, H. M.; Yamamoto, N.; Bui, K.; Papavasiliou, D. V.; Maruyama, S.; Wardle, B. L.; J. Phys. Chem. (C), 2010, 114, 8851-8860.

4. Lee, S. H.; Kim, J. H.; Choi, S. H.; Kim, S. Y.; Kim, K, W.; Youn, J, R.; Polym. Int., 2009, 58, 354-361.

5. Lew, C. Y.; Dewaghe C.; Claes, M.; Polymer-carbon nanotube composites; McNally, T.; Pötschke, P., Eds.; Woodhead Publishing Limited: Cambridge, 2011, Chapter 2.

6. Mari, D.; Schaller, R.; Mater. Sci. Eng. (A), 2009, 521-522, 255-258.

7. Krause, B.; Pötschke, P.; Häußler, L.; Comp. Sci. Technol., 2009, 69, 1505-1515.

8. Villmow, T.; Pegel, S.; Pötschke, P.; Wagenknecht, U.; Compos. Sci. Technol., 2008, 68, 777-789.

9. Richter, S.; Saphiannikova, M.; Jehnichen, D.; Bierdel, M.; Heinrich, G.; Express Polym. Lett., 2009, 3, 753-768.

10. Pegel, S.; Pötschke, P.; Petzold, G.; Alig, I.; Dudkin, S. M.; Lellinger, D.; Polymer, 2008, 49, 974984.

11. Park, D. H.; Yoon, K. H.; Park, Y. B.; Lee, Y. S.; Lee, Y. J.; Kim, S. W.; J. Appl. Polym. Sci., 2009, 113, 450-455.

12. Lellinger, D.; Xu, D.; Ohneiser, A.; Skipa, T.; Alig, I.; Phys. Sta. Sol. (B), 2008, 245, 2268-2271.

13. Chandra, A.; Kramschuster, A. J.; Hu, X.; Turng, S.; Proc. Annual Technical conference of the Society of Plastics Engineers, 2007, 3, 2184-2188.

14. Zhang, H.; Zhang, Z.; Eur. Polym. J., 2007, 43, 3197-3207.

15. Li, S. N.; Li, B.; Li, Z. M.; Fu, Q.; Shen, K. Z.; Polymer, 2006, 47, 4497-4500.

16. Kasaliwal, G. R.; Villmow, T.; Pegel, S.; Pötschke, P.; Polymer-carbon nanotube composites; McNally, T.; Pötschke, P., Eds.; Woodhead Publishing Limited: Cambridge, 2011, Chapter 6.

17. Cipriano, B. H.; Kota, A. K.; Gershon, A. L.; Laskowski, C. J.; Kashiwagi, T.; Bruck, H. A.; Raghavan, S. R.; Polymer, 2008, 49, 4846-4851.

Figure 1: FE-SEM micrographs of masterbatch PC/ABS-MWCNT nanocomposites with 5.0 wt. \% of carbon nanotubes obtained with $400 \mathrm{rpm}$ at 260 ㄷ: a) agglomerate of carbon nanotubes located in PC component, b) carbon nanotubes located in PC component. 
Figure 2: Light transmission microscope images of PC/ABS-MWCNT nanocomposites of various nanofiller concentrations obtained with $400 \mathrm{rpm}$ at 260 ㅇ $\mathrm{C}$ by masterbatch dilution: a) $1.0 \mathrm{wt}$. \%, b) $3.0 \mathrm{wt}$. \%.

Figure 3: Particle distribution histograms of PC/ABS-MWCNT nanocomposites obtained with $400 \mathrm{rpm}$ at $260 \stackrel{\circ}{ }$ C with masterbatch dilution method.

Figure 4: Light transmission microscope images of PC/ABS-MWCNT nanocomposites with $1.5 \mathrm{wt}$ \% nanofiller injected at $280 \circ \mathrm{C}$ : a) masterbatch dilution in injection molding machine, $50 \mathrm{mms}^{-1}, \mathrm{~b}$ ) masterbatch dilution in extruder, $50 \mathrm{mms}^{-1}$, c) masterbatch dilution in injection molding machine, 100 $\mathrm{mms}^{-1}$, b) masterbatch dilution in extruder, $100 \mathrm{mms}^{-1}$; long arrows point center of the cross-section, short arrows indicate geometry of the sample.

Figure 5: MWCNT distribution in PC/ABS-MWCNT of 5.0 wt. \% nanofiller injected with $50 \mathrm{mms}^{-1}$ at 260 oc.

Figure 6: Scheme of Van der Pauv electrical conductivity testing method.

Figure 7: Electrical conductivity of PC/ABS-MWCNT nanocomposites processed with masterbatch dilution method with $400 \mathrm{rpm}$ at $260{ }^{\circ} \mathrm{C}$ compared to PC-MWCNT material reported at ${ }^{16}$.

Figure 8: Electrical conductivity dependence on injection velocity for PC/ABS-MWCNT nanocomposites with different filler content and processed at $280 \stackrel{\circ}{ } \mathrm{C}$.

Figure 9: Electrical conductivity dependence on injection speed for PC/ABS-MWCNT nanocomposite of 5.0 wt. \% processed at $280 \stackrel{\circ}{ } \mathrm{C}$.

Figure 10: Electrical conductivity dependence on melt temperature during injection molding for PC/ABSMWCNT nanocomposite of $5.0 \mathrm{wt}$. \% processed with injection speed of $25 \mathrm{~mm} / \mathrm{s}$.

Table 1: Results of particle distribution measurements on PC/ABS-MWCNT nanocomposites obtained with masterbatch dilution (5.0 wt. \%), $400 \mathrm{rpm}$ at $240 \stackrel{\circ}{ } \mathrm{C}$.

\section{MWCNT concentration}

\section{$\begin{array}{lll}0.5 \text { wt. } \% & 1.0 \text { wt. } \% & 3.0 \text { wt. } \%\end{array}$}

\begin{tabular}{cccc}
\hline $\begin{array}{c}\text { Average } \\
\text { particle area }\left[\mu \mathrm{m}^{2}\right]\end{array}$ & 375.9 & 286.2 & 174.4 \\
$\begin{array}{c}\text { Average } \\
\text { particle length }[\mu \mathrm{m}]\end{array}$ & 24.4 & 26.5 & 28.6
\end{tabular}

Table 2: Electrical conductivities after various processing paths carried out on PC/ABS-MWCNT nanocomposite injected at 280 두 ; samples $\mathrm{MB}$ were obtained by masterbatch dilution in extruder and DD by masterbatch dilution in injection molding.

$$
\mathrm{MB}^{[1]} \quad \mathrm{DD}^{[1]}
$$

\section{$\begin{array}{llll}1.5 & \text { wt. } \% & 3.0 \text { wt. } \% & 1.5 \text { wt. } \% \quad 3.0 \text { wt. } \%\end{array}$}




\begin{tabular}{|c|c|c|c|c|}
\hline Compression (a) & $1.62 \mathrm{E}-01$ & $2.38 \mathrm{E}-01$ & - & - \\
\hline Injection (b) $10 \mathrm{mms}^{-1}$ & - & $8.29 \mathrm{E}-03$ & $3.52 \mathrm{E}-04$ & $6.94 \mathrm{E}-03$ \\
\hline (b) $100 \mathrm{mms}^{-1}$ & - & $3.81 \mathrm{E}-03$ & 1.97E-04 & $2.76 \mathrm{E}-03$ \\
\hline Compression (c) & $3.18 \mathrm{E}-01$ & $1.76 \mathrm{E}-01$ & - & - \\
\hline Compression (d / $\left.10 \mathrm{mms}^{-1}\right)$ & - & $3.73 E-01$ & $5.44 \mathrm{E}-02$ & $1.98 \mathrm{E}-01$ \\
\hline (d / $100 \mathrm{mms}^{-1}$ ) & - & 3.21E-01 & 5.97E-02 & 2.47E-01 \\
\hline
\end{tabular}


GRAPHICAL ABSTRACT

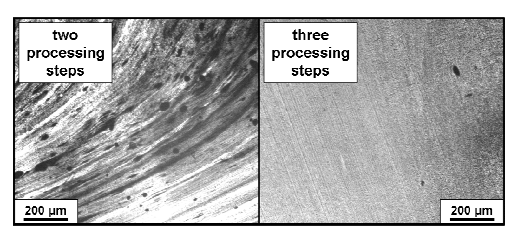

John Wiley \& Sons, Inc. 


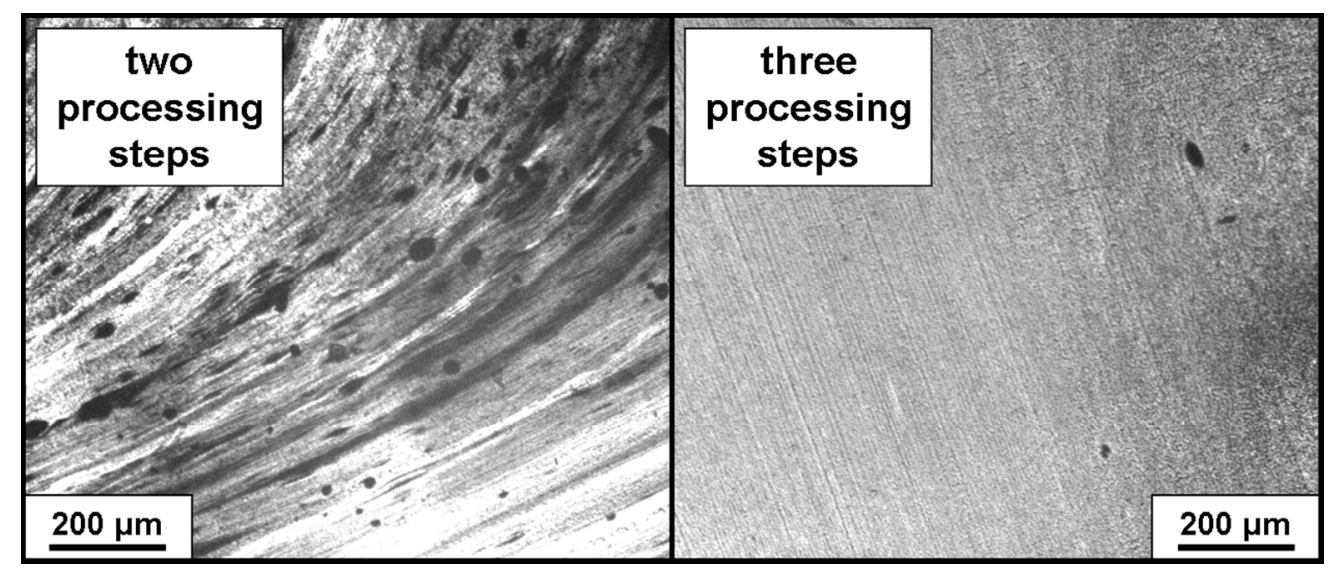

$212 \times 89 \mathrm{~mm}(150 \times 150 \mathrm{DPI})$

John Wiley \& Sons, Inc. 


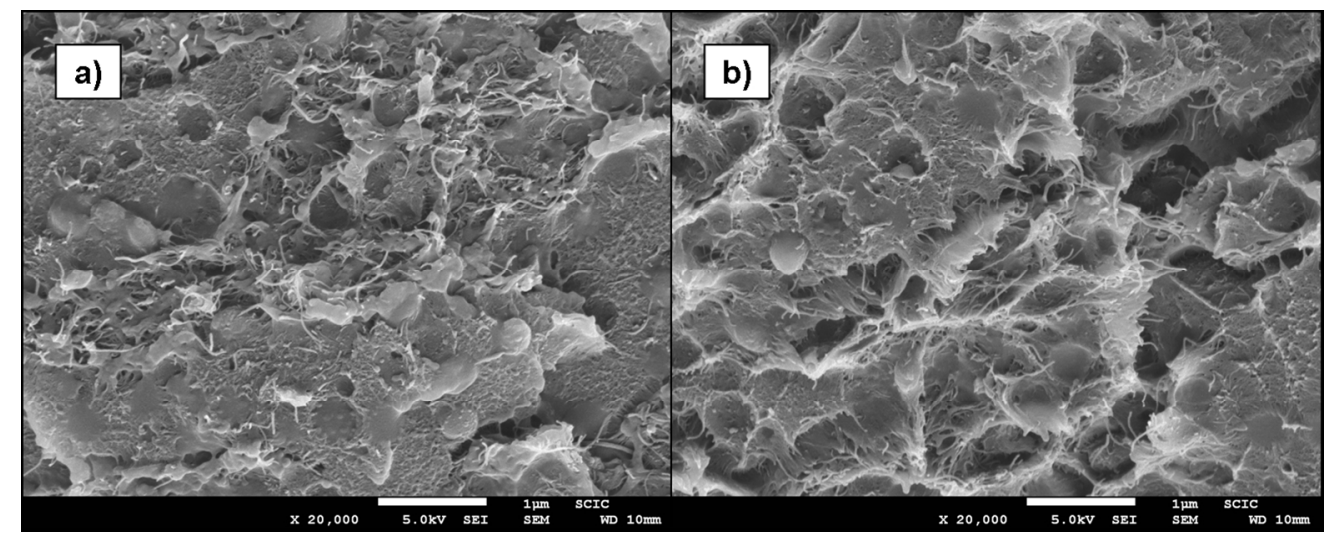

Figure 1: FE-SEM micrographs of masterbatch PC/ABS-MWCNT nanocomposites with 5.0 wt. \% of carbon nanotubes obtained with $400 \mathrm{rpm}$ at $260^{\circ} \mathrm{C}$ : a) agglomerate of carbon nanotubes located in PC component, b) carbon nanotubes located in PC component.

$255 \times 102 \mathrm{~mm}(150 \times 150 \mathrm{DPI})$ 


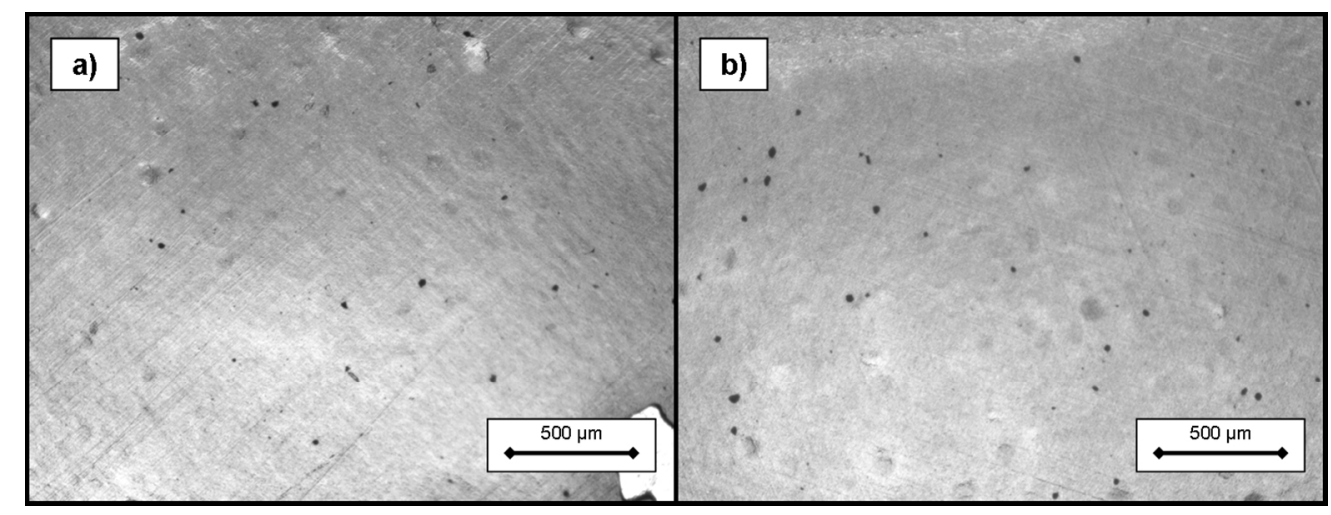

Figure 2: Light transmission microscope images of PC/ABS-MWCNT nanocomposites of various nanofiller concentrations obtained with $400 \mathrm{rpm}$ at $260^{\circ} \mathrm{C}$ by masterbatch dilution: a) $1.0 \mathrm{wt}$. \%, b) $3.0 \mathrm{wt}$. \%. $246 \times 93 \mathrm{~mm}(150 \times 150 \mathrm{DPI})$ 


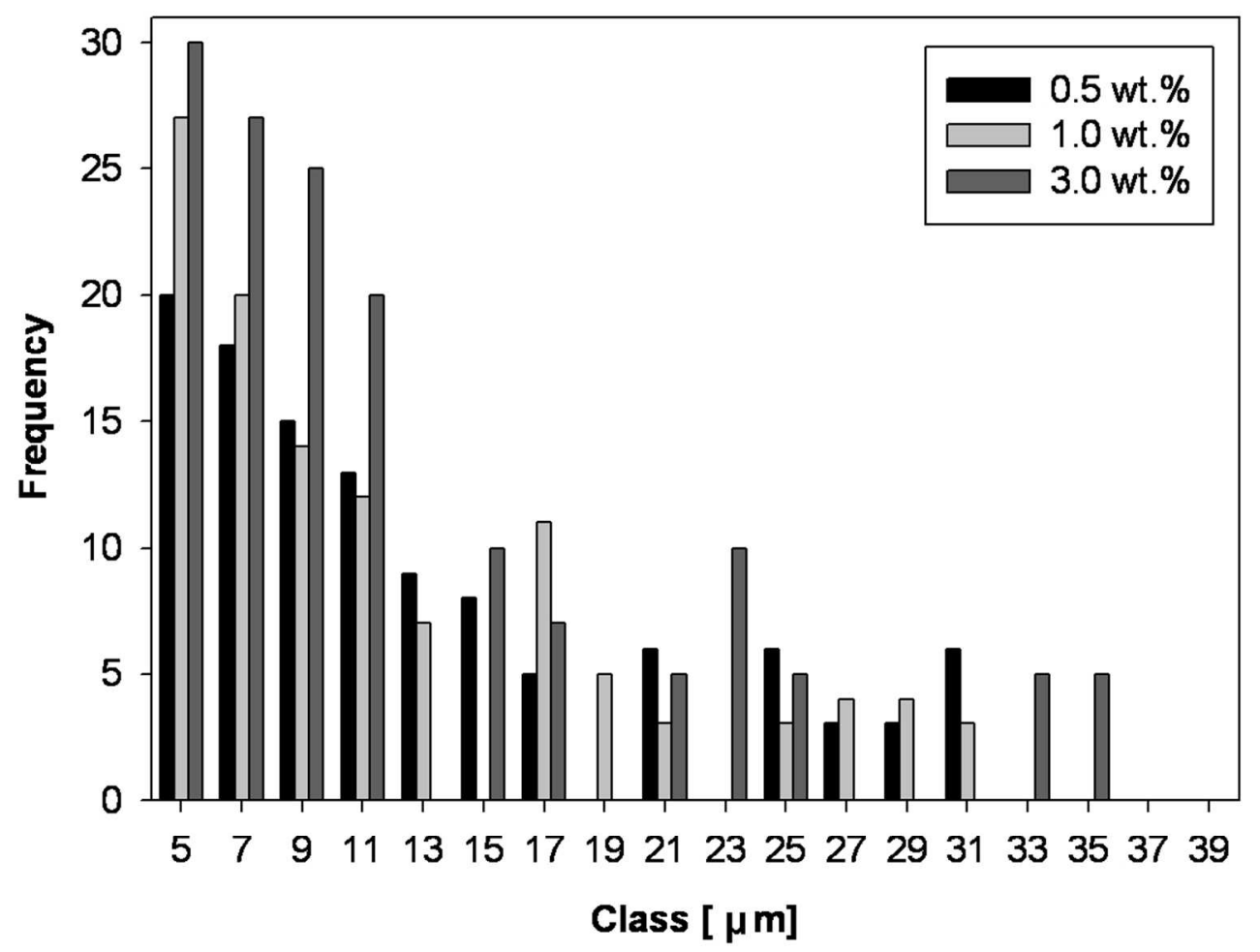

Figure 3: Particle distribution histograms of PC/ABS-MWCNT nanocomposites obtained with $400 \mathrm{rpm}$ at 260 ${ }^{\circ} \mathrm{C}$ with masterbatch dilution method. $196 \times 150 \mathrm{~mm}(150 \times 150 \mathrm{DPI})$ 


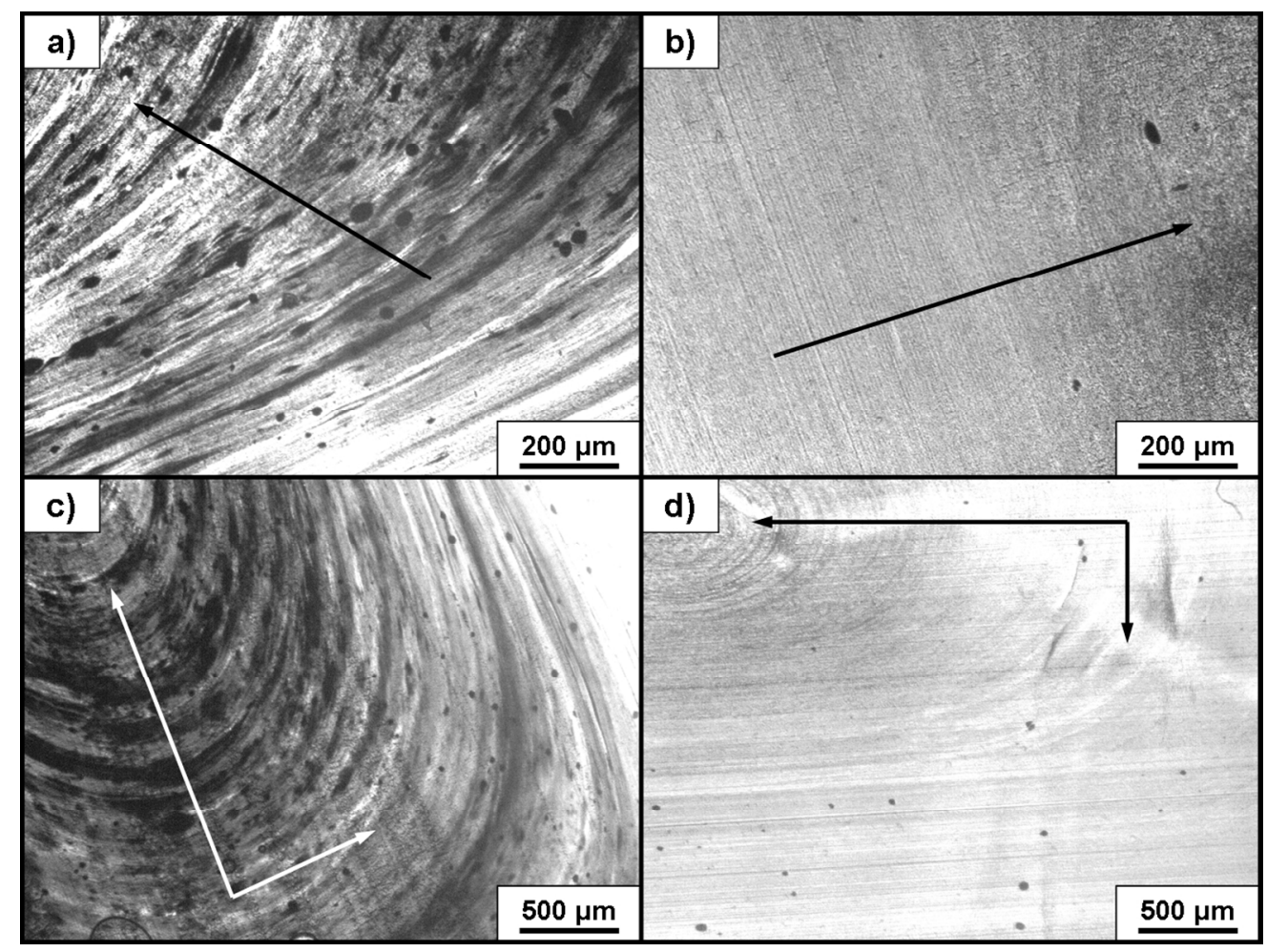

Figure 4: Light transmission microscope images of PC/ABS-MWCNT nanocomposites with 1.5 wt. \% nanofiller injected at $280^{\circ} \mathrm{C}$ : a) masterbatch dilution in injection molding machine, $50 \mathrm{mms}-1$, b) masterbatch dilution in extruder, $50 \mathrm{mms}-1, \mathrm{c})$ masterbatch dilution in injection molding machine, 100 mms-1, b) masterbatch dilution in extruder, $100 \mathrm{mms}-1$; long arrows point center of the cross-section, short arrows indicate geometry of the sample. $238 \times 178 \mathrm{~mm}(150 \times 150 \mathrm{DPI})$ 


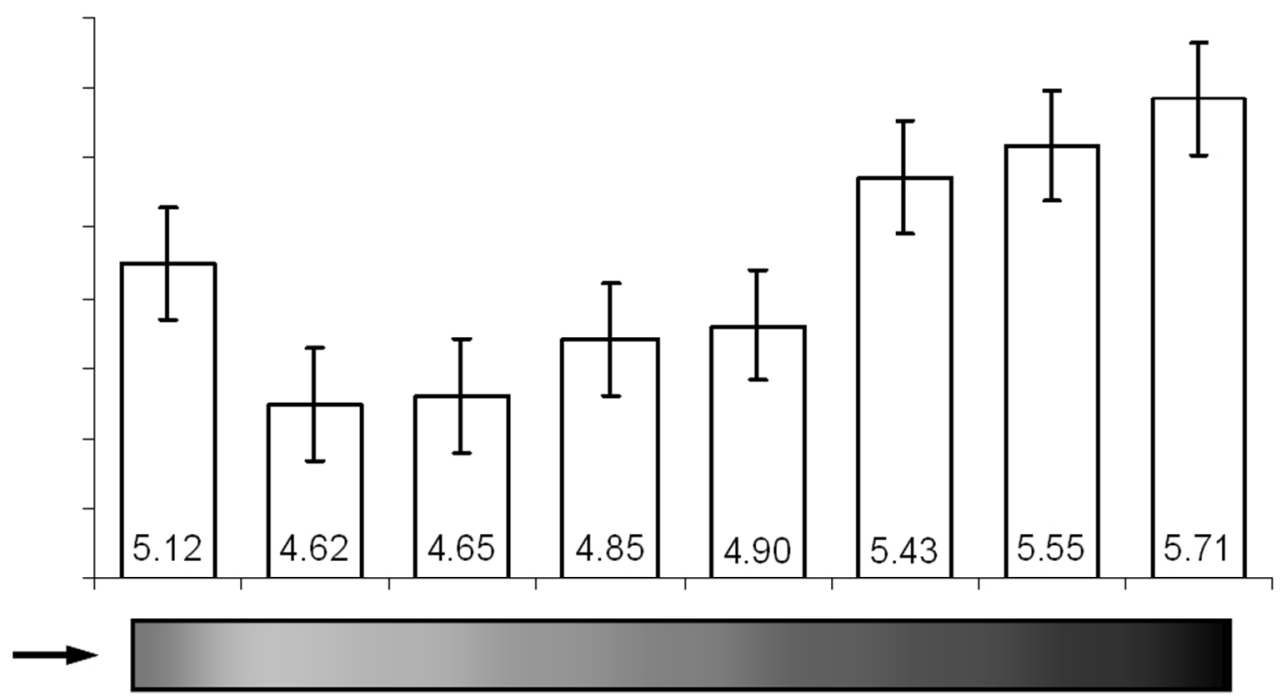

Figure 5: MWCNT distribution in PC/ABS-MWCNT of 5.0 wt. \% nanofiller injected with 50 mms -1 at 260 ' $\mathrm{C}$. $160 \times 88 \mathrm{~mm}(150 \times 150 \mathrm{DPI})$ 


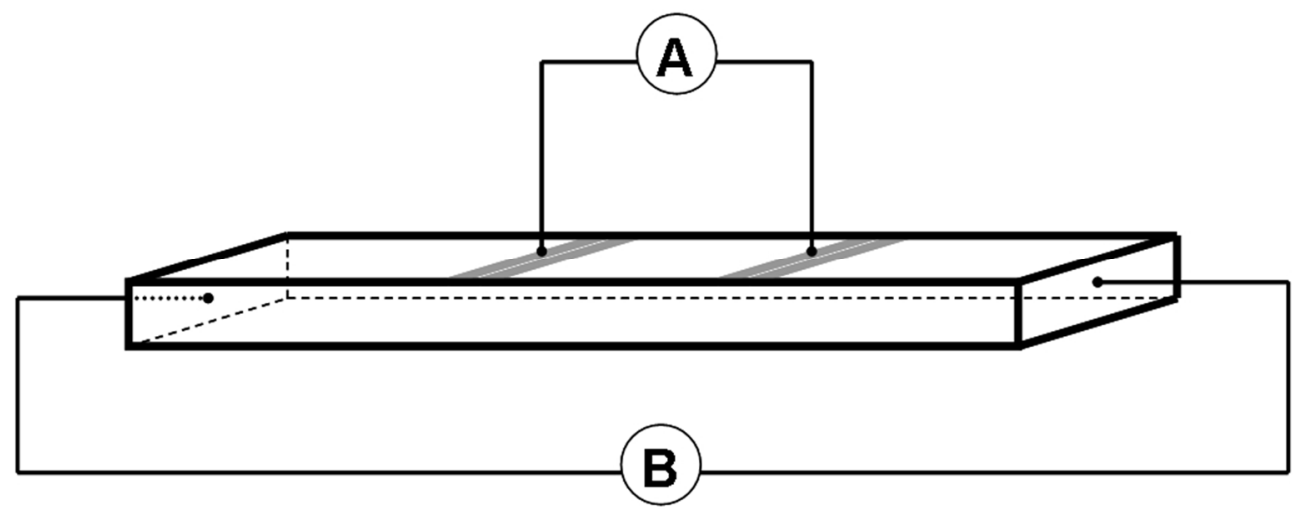

Figure 6: Scheme of Van der Pauv electrical conductivity testing method. $173 \times 69 \mathrm{~mm}(150 \times 150 \mathrm{DPI})$ 


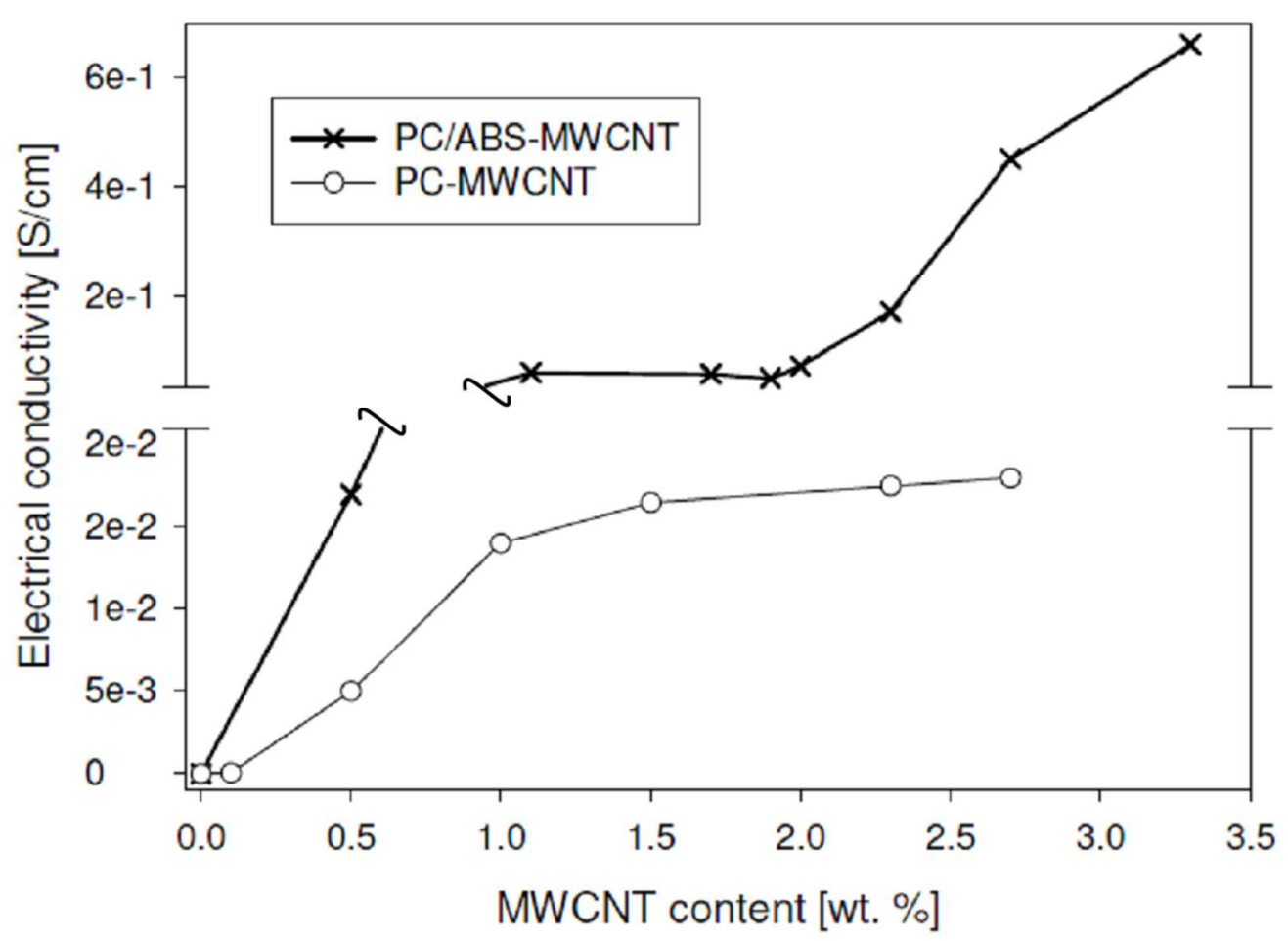

Figure 7: Electrical conductivity of PC/ABS-MWCNT nanocomposites processed with masterbatch dilution method with $400 \mathrm{rpm}$ at $260^{\circ} \mathrm{C}$ compared to PC-MWCNT material. $179 \times 130 \mathrm{~mm}(150 \times 150 \mathrm{DPI})$ 


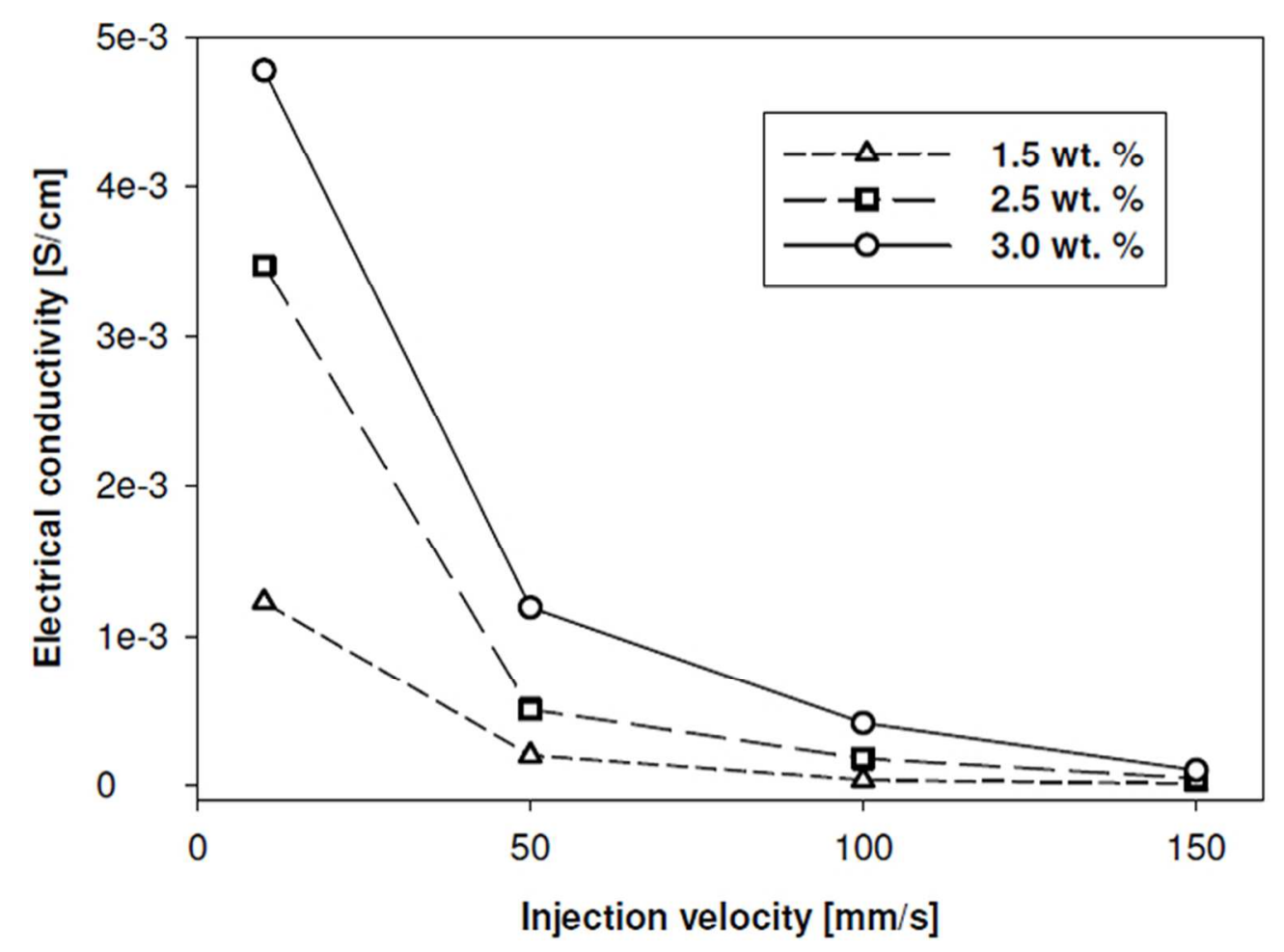

Figure 8: Electrical conductivity dependence on injection velocity for PC/ABS-MWCNT nanocomposites with different filler content and processed at $280^{\circ} \mathrm{C}$. $177 \times 129 \mathrm{~mm}(96 \times 96 \mathrm{DPI})$ 


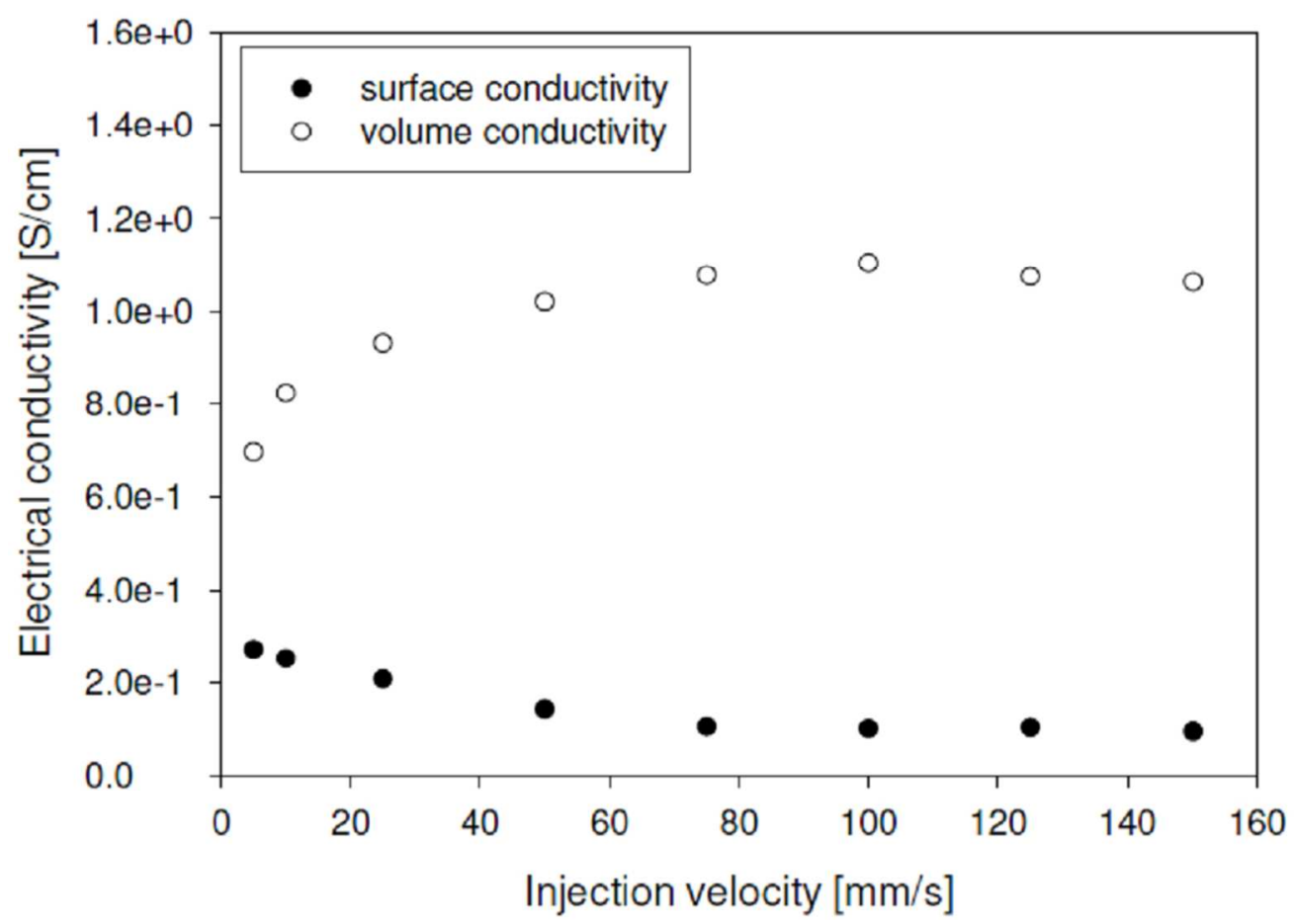

Figure 9: Electrical conductivity dependence on injection speed for PC/ABS-MWCNT nanocomposite of 5.0 wt. \% processed at $280^{\circ} \mathrm{C}$.

$177 \times 126 \mathrm{~mm}(150 \times 150 \mathrm{DPI})$ 


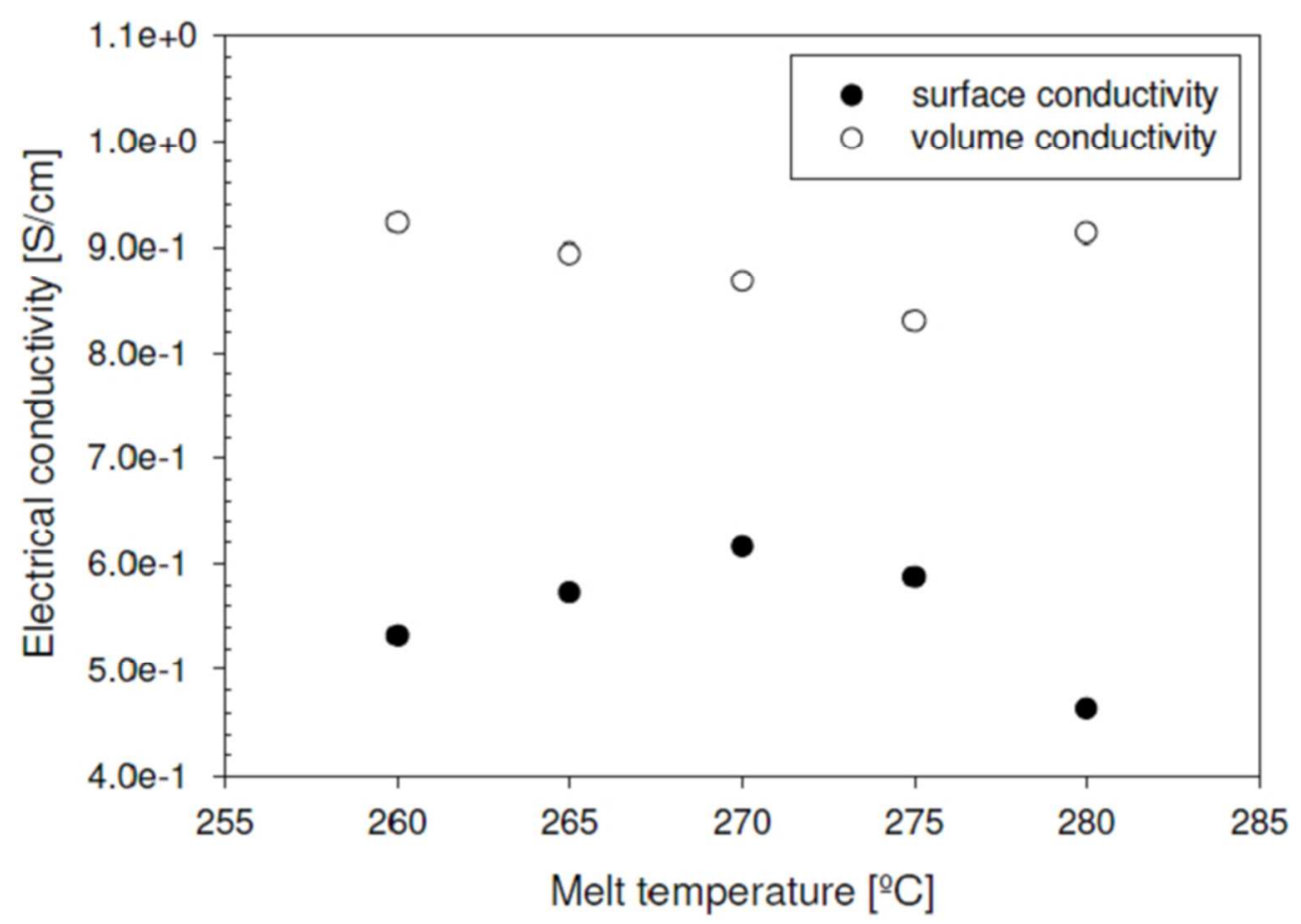

Figure 10: Electrical conductivity dependence on melt temperature during injection molding for PC/ABSMWCNT nanocomposite of 5.0 wt. \% processed with injection speed of $25 \mathrm{~mm} / \mathrm{s}$.

$178 \times 124 \mathrm{~mm}(102 \times 102 \mathrm{DPI})$ 